\title{
PROCEEDINGS AND REPORTS OF UNIVERSITIES COLLEGES, COUNCILS AND ASSOCIATIONS
}

\author{
GREAT BRITAIN
}

\author{
BRITISH ORTHOPAEDIC ASSOCIATION
}

\author{
SPRING MEETING, 1962
}

The spring meeting of the British Orthopaedic Association was held in Margate from May 3 to 5 , 1962. The President, Mr F. W. Holdsworth, was in the chair.

Pes cavus-Dr D. Brewerton, $\operatorname{Dr} P$. Sandifer and $M r R$. Sweetnam (London) said that information about the cause of pes cavus was scanty. The most commonly held belief was that it was the result of muscular imbalance associated with some neurological abnormality. Investigation of 629 patients seen between 1949 and 1958 at the Royal National Orthopaedic Hospital showed that in only 26 per cent was there any recorded evidence of neurological involvement. Since 1959 seventy-seven new patients suffering from this condition had been subjected to full neurological investigation, including electromyography and muscle biopsy. In two-thirds of these patients there was evidence of neurological abnormality. Thirty-three per cent suffered from peroneal muscular dystrophy and 44 per cent had spina bifida. The authors had not found a consistent pattern of muscle imbalance, but they had no doubt that the deformity did result from some muscular incoordination. $\mathrm{Mr} \mathrm{W}$. Sayle-Creer (Salford) asked if microscopy showed any damage to the plantar fascia, and whether the contraction of it was primary or secondary. $M r W . J . W$. Sharrard (Sheffield) asked what was the definition of pes cavus. He had seen a patient with pes cavus, without demonstrable neurological change, who at necropsy was found to have considerable cord damage. Professor J. I. P. James (Edinburgh) asked what was the mechanism of deformity, and if biopsy of the intrinsic muscles had been done. Mr Sweetnam said in reply that the plantar fascia was not examined because it was considered that the changes in it were secondary. He did not think there was any scientific definition of pes cavus. Clawing of the toes was not always present, and sometimes it was late in developing. Biopsy of the intrinsic muscles had been inconclusive, and the absence of any pattern of muscular weakness made it difficult to determine the actual mechanism of the deformity.

Tarsal movements-Mr E. Shephard (Maidstone) presented a film demonstrating the movements that took place in the mid-tarsal and subtalar joints. The peritalar movements were of the ball-and-socket type, about an oblique axis at 42 degrees to the sole of the foot, and inclined 16 degrees medial to the vertical plane, passing through the long axis of the foot between the first and second toes. A considerable range of movement was possible. The mid-tarsal joint was divided into a ball-and-socket joint and a saddle-shaped joint. Movement was restricted to a small range by the ligaments. The axis of movement made an angle of 52 degrees with the sole and 57 degrees with the bony axis of the foot passing between the first and second toes.

Osteomyelitis of the patella-Mr $D . K$. Evans (Sheffield) reported five cases of osteomyelitis of the patella. They were acute, subacute or chronic. The two acute lesions occurred in children, and one presented with an abscess subcutaneously. Without radiographs the bony origin might be overlooked. They were treated with splintage and antibiotics. Two subacute infections presented with an effusion in the knee and intermittent pyrexia. Patchy decalcification was present, and ultimately superficial sequestration. Healing followed sequestrectomy. In one case the disease was chronic: the patient was twenty-eight years of age, and the lesion was brought to light by an injury. Patellectomy gave a good result. The condition was not found before the age of five years because ossification was not sufficient. In children the knee joint was not involved because of the thick layer of cartilage. $M r I$. $S$. Smillie (Dundee) said that other differential diagnoses to be remembered were abnormalities of ossification and Sinding-Larsen-Johannson's disease.

Charnley compression arthrodesis of the hip-Mr J. B. Morris (New Zealand) pointed out that this type of arthrodesis was developed to overcome the difficulty of obtaining bony ankylosis. He had 
reviewed seventy-one patients subjected to this operation since 1957 . The best results were obtained by conical reaming of the femoral neck, which fitted into a corresponding hole reamed in the acetabulum, so that it fitted like a cork in a bottle. Compression and internal fixation were obtained by a lag screw and spring. A bone graft was placed between the pelvis and the greater trochanter, and this was supplemented by bone paste. A hip spica was maintained for eight weeks. By this means union had been obtained in 88 per cent. Failure of fusion occurred in eight patients: in five it was ascribed to dense sclerosis of the femoral head, in one to inadequate immobilisation, and in two to spontaneous fracture of the femoral neck. Spontaneous fractures had occurred in six patients: four in the femoral neck and two in the shaft. In five patients the fracture occurred in the early months. It was probably due to weakening of the calcar during the process of reaming. Mr Norman W. Roberts (Liverpool) agreed that conical reaming of the neck of the femur and the acetabulum provided a good fit, but said that it was difficult to estimate the degree of bony union, and sometimes when it looked satisfactory to begin with it turned out to be only fibrous union. Mr J. Charnley (Manchester) said that it must be appreciated that arthrodesis of the hip was not an easy operation. It was essential to have the right tools if this type of arthrodesis was to be carried out, and attention must be given to details of technique if good results were to be obtained. He agreed that fractures occurring in the neck might be the result of damage to the calcar femorale during reaming. $M r J$. S. Batchelor (London) thought that spica immobilisation in such cases was inefficient, and he preferred a Stryker frame. He thought that fractures of the femoral neck were more likely to occur from interference with the blood supply. $\mathrm{Mr}$ Morris replied that he found eight weeks' immobilisation was all that was required, although many different periods had been tried. When screw fixation and compression had not been used fracture of the neck was more common. He thought that this might be due to a short fibrous union developing early between the neck and the pelvis which protected it from strain.

Mould arthroplasty of the knee-Mr G. Platt (Aylesbury) said that two completely stiff knees were a big disability. Even a few degrees of movement were a great help. He showed in a film how a shaped Vitallium mould was fitted into the joint, covering the femoral condyles, after excision of the joint surfaces without interference with the ligaments. He had done the operation twenty-eight times. In sixteen cases the pain was relieved, in five it was slight, and in four severe. In two cases the prosthesis had been removed, and the underlying bone was found to be covered with smooth white fibrocartilage. Mr M. H. M. Harrison (Birmingham) asked if genu valgum or varum could be corrected at the time of operation. Mr R. Merryweather (Cheltenham) said that experience with the Walldius arthroplasty had given satisfactory results. $M r L$. G. P. Shiers (London) said that this procedure overcame the problem of compression of the soft bone, but the range of movement was not so good as with the hinged prosthesis. Mr Platt, replying, said that knock-knee could quite easily be corrected at operation, but posterior subluxation of the tibia was a contra-indication. He was opposed to the hinge because it could break, because the bone into which it was fitted was unsuitable, and because if it went wrong severe shortening resulted.

Surgery of the tendons of the hand in rheumatoid arthritis-Mr O. J. Vaughan-Jackson (London) described the way in which attrition ruptures occurred in the extensor tendons of the hand. The ruptures were painless, and always occurred from the little towards the index finger. They were caused by friction of the tendons on a sharp edge of the lower end of the ulna. If allowed to persist, the flexion deformity of the metacarpo-phalangeal joints resulted in subluxation and degeneration of the articular cartilage. Similar attrition ruptures were found in the flexor group of muscles; when this had happened in the carpal tunnel it was not uncommon to find a rough area of bone which might have accounted for the rupture. In repairing the tendons this area was recessed to avoid friction. Triggering of the fingers developed from involvement of the flexor tendons by granulation tissue and was corrected when the tendons were freed. Spontaneous rupture of the sublimis tendon in a finger led to the development of the typical "swan-neck" deformity. If the tendon was repaired before the deformity had become fixed, and before joint changes had developed, good function could be restored. Ulnar deviation of the fingers, which was so common in rheumatoid arthritis, resulted from excessive swelling of the synovium, which caused displacement of the extensor tendon to the ulnar side. Synovectomy, done in time, and replacement of the tendon restored good function. It was not yet known how long the benefits of synovectomy would last, but it was important to appreciate that many of the irreversible changes in joints were secondary to the deformity, and if this was corrected in time these changes could be prevented. Mr D. L. Savill (Edinburgh) did not agree that a bony spicule was the usual cause of attrition ruptures. Ruptures were more often due to direct invasion of the tendons. Early decompression of the carpal tunnel before a nerve lesion occurred improved function. He undertook synovectomy of the metacarpo-phalangeal joints earlier and earlier. $\mathrm{Mr} M$. C. Wilkinson (Black Notley) was optimistic about the lasting benefit to be gained from synovectomy. Disability in the hand sometimes resulted from binding down of the extensor tendons on the back of 
the wrist. $M r G . N$. Golden (Guildford) said that joint deformities could be prevented by treatment of muscles and tendons. Why did the synovial bulge of the metacarpo-phalangeal joint occur on the radial side? Professor J. I. P. James (Edinburgh) asked if active destruction of ligaments played a part in the deformity, and if synovectomy prevented bone destruction. Mr O. J. Vaughan-Jackson, replying, agreed that tendon ruptures were not always due to a spike of bone, but when they occurred in a sheath it was always at a tight spot. He did not think that actual invasion of the tendon often occurred. He did not know why ulnar deviation occurred but it might be due to posture. Occasionally radial deviation was seen. Destruction of ligaments might occur late. He did not know how long the effects of synovectomy would last.

Auto-immunity-Dr L. E. Glynn (Taplow) defined auto-immunity as being the state of an animal that has reacted immunologically to one or more of its own tissue constituents. In earlier work auto-immunity had been rejected as a cause of disease because of the failure to produce it experimentally, but there was now an increasing acceptance of the pathogenic significance of auto-immunity after finding auto-immune antibodies in acquired haemolytic anaemia, and the experimental development of such conditions as encephalitis, thyroiditis, aspermatogenesis, presumably as the result of such reactions. Great technical advances had been made in detecting immune reactions, and in the understanding of the mechanism of antibody development. He described the experimental production of auto-immunity by means of Freund's complete adjuvant. In this technique a piece of the animal's own tissue was emulsified in oil, to which was added acid-fast bacilli. This greatly enhanced the antigenicity of the tissue. If a foreign fibrin was injected into a sensitive animal it became walled off by reactive cells, forming a nodule like that found in rheumatoid arthritis. If an animal's own fibrin was injected after auto-immunity to the fibrin had been induced, similar nodules would develop. Injections of fibrin into joints would produce changes resembling those found in rheumatoid arthritis. There was normally some mechanism which prevented auto-immune reactions from developing, but this mechanism could occasionally break down, and the result of such a breakdown might contribute to the development of rheumatoid arthritis. Mr F. G. St C. Strange (Canterbury) had removed large cysts of fibrin from the subdeltoid and popliteal regions. Did these persist because of an auto-immune reaction to fibrin, and did the same apply to loose bodies? $\mathrm{Mr} \mathrm{O}$. J. Vaughan-Jackson (London) asked whether excision of the fibrin at the margin of joints could break the vicious circle of autoimmunity. Dr Glynn, replying, said that if the persistence of fibrin in a joint were an auto-immune reaction it should occur quite often. He had used fibrin only as an example. It might be that some substance reacted with synovium so that a synovectomy would be expected to produce a cure.

Radio-ulnar fusion for defects in the forearm bones-Mr H. G. Lowe (Stafford) said that a defect in one bone in the forearm led to inequality in growth. It might be caused by osteomyelitis, congenital abnormality, osteochondroma, or trauma. Grafting the defect was difficult and unreliable. Fusion between the two bones gave better results, even though rotation was lost. In children this was easily compensated if the fusion was done in mid-rotation. He reported seven such operations carried out by $\mathrm{Mr}$ A. O. Parker. The results in all were very satisfactory. Six were done in children, and one in an adult.

The conservative approach to radial head fractures-Mr B.T. O' Connor and $M r T . K . F$. Taylor (Oxford) had reviewed fifty-eight adult patients subjected to excision of the head of the radius for comminuted or depressed fractures. It was found that in half the patients symptoms persisted in the inferior radio-ulnar joint, which showed a minor degree of upward subluxation of the radius. In radial head fractures treated conservatively this displacement did not occur. There were certain severely comminuted fractures of the radial head for which excision was essential. It might be worth considering prosthetic replacement in these. $M r A$. L. Eyre-Brook (Bristol) said that it was difficult to get comparable series of patients treated conservatively and by operation. Usually only the badly comminuted radial heads were excised. $M r J . N$. Wilson (London) asked if excision, when done, should be immediate or delayed. In severe injuries, if the interosseous ligament was damaged, it would be wise to let it heal before operating. $\mathrm{Mr} \mathrm{H}$. Osmond-Clarke (London) asked if it could be explained why sometimes a bad result followed a minor crack fracture. $M r C$. C. Jeffery (Exeter) said that the only place for a prosthesis was when very extensive damage had been done to the interosseous ligament, as shown by marked upward displacement of the radial head. Mr Taylor, replying, said that there was no clinical evidence of rupture of the interosseous membrane. After experimental excision of the head of the radius slight upward displacement was possible because of slack in the membrane, and even though the degree of displacement might be small it was sufficient to cause symptoms. After a simple crack the joint cavity might be intact so that blood could not escape, and the haemarthrosis might account for the bad result sometimes seen.

Practical points in the management of head injuries-Mr G. B. Northcroft (London) said that most head injuries were treated by orthopaedic or general surgeons. Only one patient in ten was seen by a

VOL. 44 B, NO. 3, AUGUST 1962 
neurosurgeon. It was therefore of great importance that those on the spot should have a full knowledge of immediate diagnosis and treatment. Anoxia might cause irreversible damage if not corrected quickly by keeping a clear airway and posturing, which was most important at the scene of the accident. On admission to hospital the difficulty was to decide whether operation would be necessary or not. Repeated examination was the key to diagnosis, and the level of consciousness was the yardstick to which all other signs were linked. In the simplest form, comprising 90 per cent of cases, coma was followed by progressive recovery. The extent of post-traumatic amnesia was the best estimate of the degree of brain damage. If this was less than two hours there was only concussion, but more than this indicated varying degrees of contusion. Coma followed by a lucid interval and then coma again ( 3 per cent of total) indicated an expanding space-occupying lesion, and operative decompression was urgent. In the most serious type of injury ( 7 per cent) deep coma persisted and resulted in either death or permanent disability. Decompression by burr holes should be attempted, but usually produced little or no benefit. If such patients survived they became great nursing problems; their life depended on keeping a clear airway, a fluid and electrolyte balance and good general condition. $\mathrm{Mr} H$. Osmond-Clarke (London) said that it was very important for anyone dealing with accidents to have a good knowledge of how to deal with the killing injuries, such as those of head or chest. Mr W.J. W. Sharrard (Sheffield) asked if the use of intravenous urea was helpful in reducing cerebral oedema. $\mathrm{Mr}$ Northcroft, in reply, said that it was better to refer to cerebral swelling rather than oedema. Swelling might be due to congestion of the veins or to intercellular swelling, in neither of which case would urea help. When the swelling was extracellular, urea might be useful, but it had the disadvantage that if it did not help the condition deteriorated when the urea was discontinued.

Popliteal arteriovenous aneurysm as a complication of meniscectomy-Mr J. Patrick (Glasgow) reported four cases of popliteal aneurysm complicating meniscectomy which had come to his notice. In all there had been difficulty at operation, in all a chisel-type knife had been used, and all the operations were done by junior surgeons. In three patients the aneurysm did not become obvious until after three months, but in one, a child, it was obvious at two weeks. In the two in which the anastomosis was repaired there was good recovery, but of the two in which the popliteal artery was tied, gangrene developed in one, and ischaemic contracture of the calf in the other. He emphasised that, if a chisel-type knife was used, the points should be blunt. A sandbag behind the flexed knee might approximate the artery to the capsule and render it more liable to injury. $\mathrm{Mr} \mathrm{I}$. S. Smillie (Dundee) said that while the points of the knives should not be sharp, the sharper the blade the less risk there was of doing damage. He did not think the sandbag behind the knee was a factor.

Radiographic localisation of severed tendons and of adhesions within a synovial sheath- $\mathrm{Mr} H$.J. Richards (Cardiff) said that in tendon surgery of the hand it was often helpful to know the level to which divided tendons had retracted and the extent of adhesions before definitive operation was undertaken. He had injected Hypaque into the tendon sheath and then taken antero-superior and oblique radiographs. Sometimes injection at more than one level would be necessary. Normal sheaths and tendons were demonstrated and compared with those in which the tendon had been divided. Multiple pockets in the sheath were typical of rheumatoid arthritis. $M r O$.J. Vaughan-Jackson (London) did not think that the procedure had much practical application, but it might be useful in spontaneous rupture.

A new approach to muscle function in the fingers-Mr $H$. G. Stack (Brentwood) presented a film in which the detailed anatomy of the extensor expansion of the fingers was demonstrated, and its anatomical and functional relationship to the lumbrical and interosseous muscles was shown. The way in which all these muscles interacted to produce detailed joint action was shown by means of models.

\section{CLINICAL DEMONSTRATION}

A clinical demonstration was presented at the Royal Sea Bathing Hospital. This included a section on the active surgical approach to tuberculosis by $\mathrm{Mr}$ F. G. St Clair Strange (Canterbury) and Mr P. R. Wright (Margate); emphasis was laid on getting the patients back to activity as soon as possible. Cases of spondylolisthesis were shown in which fusion of the defect in the pars interarticularis had taken place, and fusion between the loose neural arch and the laminae above. There was an exceptionally large number of interesting conditions demonstrated, particularly among the bone dysplasias, and a demonstration of pathological changes by $\mathrm{Dr}$ Harold Sterndale (Broadstairs). $M r R$. C. Baird (London) showed cases of open injuries of the hand and upper limb, some cases of gout, and the use of ultrasonics in cases of Dupuytren's contracture.

During the course of the meeting a film was shown in which Sir Harry Platt (Manchester) and Professor Bryan McFarland (Liverpool) discussed their personal recollections of Sir Robert Jones during his lifetime. 
ELECTION OF FELLOWS. MEMBERS AND ASSOCIATES

At a meeting on May 4, 1962, the following were elected.

Emeritus Fellow-B. Whitchurch Howell (London).

Fellows-J. J. Commerell (Cape Town), D. M. Dunn (Colchester), D. R. Gunn (Singapore), J. P. Jackson (Harlow Wood), E. S. Jamieson (Newmarket), G. C. Jennings (Wellington, New Zealand), M. Makin (Jerusalem), C. Manning (London), J. D. Morgan (Oxford), O. R. Nicholson (Auckland, New Zealand), A. G. O`Malley (Liverpool), G. Parker (Middlesbrough), E. L. S. Robertson (Trinidad), Harman G. Smith (Auckland, New Zealand), A. K. Talwalkar (Bombay), F. G. Ward (Ashford), J. Wishart (Bradford), H. W. Wouters (Utrecht), P. R. Wright (Margate).

Members-T. G. Barlow (Salford), J. Chalmers (Edinburgh), R. C. Farrow (London), L. W. Godfrey (Aylesbury), E. J. Hargadon (Manchester), A. C. Hume (Colchester), A. Katz (London), H. Klein (Johannesburg), M. L. H. Lee (Oxford), R. S. M. Ling (Edinburgh), F. H. Moore (Cork), H. A. Oatley (London), D. C. Paterson (Adelaide), A. E. Pritchard (Liverpool), J. T. Scales (London), W. R. Welply (Winnipeg), V. H. Wheble (Manchester).

Associates-E. G. Ahern (Vereeniging, South Africa), G. C. W. Baker (Edinburgh), B. W. Broadhurst (Pyrford), P. J. Chesterman (London), H. W. M. Collymore (Trinidad), M. M. Diab (Cairo), M. G. Dorostkar (Teheran), W. G. S. Fung (Singapore), A. C. Giannikas (Derby), J. G. Gill (Halifax), J. M. S. Hague (Cardiff), D. W. M. Haw (London), T. E. Jeffreys (London), K. Kamberoglou (Athens), J. R. Kirkup (Bath), C. C. D. Martin (Birmingham), P. H. Osterberg (London), S. T. S. Raj (Madras), G. Ramaswami (Cardiff), R. G. Redhead (London), S. Theodorou (Athens), E. M. Wahb (Cairo), J. Watson-Farrar (Norwich), A. B. Young (Glasgow).

\section{ROBERT JONES GOLF CUP}

The 1962 competition for the Robert Jones Golf Cup was played in good weather at Princes, Sandwich, on the afternoon of May 2. Sixteen enthusiasts took part but the course was too long and difficult for most of them. The cup was won by Mr G. P. Arden of Windsor with the excellent return of $85-13=72$. Mr R. H. Maudsley and Mr N. J. Blockey tied for second place with a net scorc of 75 .

Mr John Todd has been elected Captain in succession to Mr R. Stirling.

It is hoped to hold the next competition at Lindrick near Sheffield on the occasion of the Spring Meeting of 1963.

\section{SCIENTIFIC SOCIETIES AND REGIONAL ORTHOPAEDIC CLUBS}

\section{THE BONE AND TOOTH SOCIETY}

Abstracts of papers delivered at a meeting held at the Royal National Orthopaedic Hospital, 234 Great Portland Street, London, W.1, on January 31, 1962.

Histopathology of osteoporosis-Dr H. A. Sissons (London) applied the term " osteoporosis " to any condition with reduction in the amount of bone: the degree of calcification of the bone tissue was not affected, unless osteomalacia was also present. Osteoporosis could be either local or general, and could have a variety of causes. The practical recognition of osteoporosis in morbid anatomical material demanded information on the amount of bone tissue normally present at a given site. Such quantitative data were scarce, but published work indicated a reduction in general bone mass (Ingalls, N. W. (1931): American Journal of Anatomy, 48, 45), and in the amount of bone present at particular sites with increasing age (Amprino, R., and Bairata, A. (1936): Zeitschrift für Zellforschung, 24, 439; Sissons, H. A., Jowsey, J., and Stewart, L. (1960): Proceedings of the Second International Symposium on X-ray Microscopy, p. 205; Jowsey J. (1960): Clinical Orthopaedics, 17, 210). This age variation, together with individual variation, made the recognition of minor degrees of osteoporosis difficult. Histologically, interest centred on the mechanism of production of the bone changes. The normal skeleton presented continuously active, but balanced, bone deposition and bone resorption: reduction in the amount of skeletal tissue could result from either an increase in bone resorption or a decrease in bone deposition. It was also possible that "turnover" of bone might be balanced with a reduced amount of tissue present; this would represent osteoporosis at a non-progressive stage. Recent work suggested that, in some types of local rarefying bone disease, there could actually be an increased rate of bone deposition, together with an even greater rate of bone resorption. The increasing porosity of the ageing skeleton appeared to be caused by an increase in bone resorption (Sissons, H. A., Jowsey, J., and Stewart, L., 1960, loc. cit.: Jowsey 1960, loc. cit.), but little morphological evidence was available on the activity of this process, or of bone formation, in idiopathic osteoporosis.

VOL. 44 B, No. 3, AUgiust 1962 
Changes in the spine in osteoporosis-Professor D. H. Collins (Sheffield) presented figures of the incidence and severity of vertebral osteoarthritis derived from the pathological examination of over 600 spines in necropsies at acute general hospitals. Sagittal slabs of lumbar vertebrae were examined grossly for texture and softness. When osteomalacia, tumour, Paget's and other diseases had been excluded, osteoporosis could be defined as a reduction in calcified bone mass in a unit volume of anatomical bone. This was measured in one series by determining the specific gravity of the intact centrum of a vertebral body and in another series by measuring the radiographic density of a slab of bone one centimetre thick. Many calcium estimations were made, ranging from about 40 to 100 milligrams per cubic centimetre of bone volume. The density of human lumbar vertebrae measured in these ways formed a smooth distribution curve with a single peak in the case of either or both sexes, suggesting that there were not two populations, one with normal and one with diseased bones, but a biological range of variation. Average bone density regressed smoothly with age and began to fall below the mean for the whole series at about the age of forty-five in women and about ten years later in men. Bones at the lower end of the density scale could be called osteoporotic, but were distinguished from those of normal persons only by the open texture of the cancellum, the thin cortex and their softness. The osteoporotic could only be separated from the normal vertebrae by fixing an arbitrary lower limit to what might be called normal bone density. In the present series this arbitrary level was fixed at what seemed to correspond with the appearance of those gross features of texture and softness and radiographic pattern which are usually described as osteoporotic. It was then found that, depending on the method of examination, 12 to 17 per cent of all the spines examined could be assessed as porotic. The incidence of osteoporosis so defined increased progressively with age; the sex ratio (male : female) in one series was about $1: 2$ and in the other about $1: 1$. Primary spinal osteoporosis therefore presented the characteristics of an involutional process, and seemed to come within the pathological category of involutional or senescent atrophy.

Diagnosis of osteoporosis- $\operatorname{Dr}$ E. Barnett, $\operatorname{Dr} J . S$. Beck and $\operatorname{Dr} B$. E. C. Nordin (Glasgow) mentioned that the histological diagnosis of osteoporosis could be made from a trephine sample of the iliac crest, which was sectioned, photographed and compared with the nine-point biopsy scale of Beck and Nordin. The only criterion was the amount of bone present. A biopsy score of less than 5 suggested osteoporosis, and by this criterion about 12 per cent of men and 23 per cent of women dying in the Western Infirmary, Glasgow, were osteoporotic. The radiographic standards of Barnett and Nordin were rather insensitive and yielded false negatives but no false positives. In severe osteoporosis the vertebral bodies became less dense than the intervertebral discs. Peripheral osteoporosis occurred only when there was already a reduction in spinal density, but spinal osteoporosis might occur in the presence of normal peripheral bones. It was concluded that generalised osteoporosis affected trabecular bone only at first and compact bone later.

Clinical aspects of osteoporosis-Professor Russell Fraser (London) said that the diagnosis of osteoporosis or bone atrophy was still largely made by exclusion of other major causes of radiologically thin bones; this occasionally needed biopsy. Even firm assessment of radiological thinning was difficult but Doyle's method (1961, British Journal of Radiology, 34, 698) for peripheral bones was hopeful although the axial skeleton seemed predominantly affected. The previous usual incrimination of defective bone formation had not been supported by tracer studies, so that calcium deficiency remained a possible cause. There were three main clinical groups: 1) complicated, 2) atypical, and 3) typical or post-menopausal and senile osteoporosis. Complicated osteoporosis included the rarer cases in which bone atrophy was part of a wider process-acromegaly, Cushing's syndrome, thyrotoxicosis or steatorrhoea. Their study was important for suggesting causes to be sought in the other types. In many typical cases a positive calcium balance could be secured by high intake of calcium, but bone growth might also be needed to restore bone strength, a difficult problem except in the young.

The relationship between osteoporosis and fracture incidence- $\operatorname{Dr} A$. M. Cooke (Oxford), in a study of the epidemiology of fractures, had found striking variations in the rates for different bones at various ages and in the two sexes. In some bones the peak was in childhood, with few cases in later life. In other bones the fractures occurred almost entirely in men of working age. In a third group the incidence was low in youth but rose sharply with age, especially in women. An example of the last type of fracture was that of the upper end of the femur, where the chance that a man of eighty would sustain a fracture as compared with a man under forty was 37 to 1 . In women of similar ages the ratio was 370 to 1 . There was clinical, radiological and pathological evidence that in some bones osteoporosis was an important factor in the increased incidence of fractures associated with age and in the female sex. There were, of course, many other factors, such as the severity of the injury, its type, how often it occurred, how it occurred, the protective and stabilising effects of muscles and ligaments, and fatigue. 
A clinical series of osteoporosis with assessment of the results of therapy-Dr $R$. G. Miller (Bedford), with the object of improved assessment of bone density in routine films of the lumbar spine, had exposed an aluminium step wedge, one millimetre to six millimetres deep, overlying the soft-tissue shadow of the liver but clear of the shadow of the spine, so that the wedge and bone shadows could be approximately compared. A series of fifty-eight patients with osteoporosis of the spine was presented. In nine osteoporosis was the predominant disease. The remainder presented some other serious disease. Seven were receiving gluco-corticoids. All were treated with androgens and oestrogens together with calcium supplements for eighteen months or longer. Thirty-eight per cent of the patients showed a good result from treatment, 43 per cent a fair result and 19 per cent a poor result. Those without complications responded best; those with chronic bronchitis and emphysema, congestive heart failure or osteoarthritis of the hip and spine in addition to osteoporosis did moderately well; those with cerebro-vascular disease responded poorly. Osteoporosis due to gluco-corticoids was halted. Unequivocal radiological improvement was objective evidence of the efficacy of treatment. Three patients showing radiological improvement were reported.

Balance studies in osteoporosis associated with thyrotoxicosis- $\mathrm{Dr} B$. A. Higgins (London) recalled that prolonged calcium, phosphorus and nitrogen balances had been performed on nine patients suffering from thyrotoxicosis (Cook, P. B., Nassim, J. R., and Collins, J. (1959): Quarterly Journal of Medicine, N.S. 28, 505). The calcium balances were negative, with raised urine and faecal calcium. The phosphorus balances were also negative, with a high urine phosphorus. Positive nitrogen balances were seen in the presence of weight loss. Adequate treatment produced a progressive fall in the urine and faecal calcium resulting in positive calcium balances. The phosphorus balances followed the calcium, and the nitrogen balances became more positive. Slightly raised serum phosphorus values found in most patients fell to normal after treatment. The serum calcium estimations were normal. A slightly raised faecal fat found in eight of the nine patients fell to normal on treatment. A negative calcium balance and high urine calcium were unaffected by doubling the calcium intake or by reducing it to 200 milligrams per day, or by administration of vitamin D orally or intramuscularly. An anabolic steroid, methyl androstenediol, had no effect on a calcium balance but improved the phosphorus and nitrogen balances. Bone biopsy performed in all cases showed no evidence of increased osteoclastic activity. The theoretical renal threshold for phosphorus was estimated in one patient by means of a phosphate infusion and found to be high normal. In three patients with myxoedema the threshold was low and was raised after adequate treatment with thyroid hormone. The data indicated rapid dissolution of bone in thyrotoxicosis of unknown cause, probably not due to primary intestinal malabsorption, negative nitrogen balance or co-existing hyperparathyroidism.

Pathogenesis of osteoporosis-Miss Irene Dallas, Mr J. MacGregor, Dr D. A. Stuart-Smith and Dr B.E. C. Nordin (Glasgow) said that the pathogenesis of osteoporosis was uncertain, but it could be produced in animals by a negative calcium balance. Diets deficient in calcium did not cause rickets unless given to very young animals and continued to the point of depressing the blood calcium. Vitamin D deficiency and low phosphorus diets, on the other hand, produced an abnormal serum calcium and therefore caused rickets or osteomalacia, seemingly because vitamin D sustained the serum calcium by direct action on bone, quite apart from its effect upon the absorption of calcium. If calcium requirement was defined as the amount needed to maintain calcium balance in adults then the mean calcium requirement was about 10 milligrams per kilogram a day, but the variation was so wide that about 7 per cent of the population of Britain might be in negative calcium balance. Analysis of 231 diet histories showed that patients with osteoporosis ate significantly less calcium than subjects with normal bones. The implication was that osteoporosis may develop in individuals whose intake was below average and who were unable to adapt to this intake. The failure of adaptation appeared to be predominantly a failure to reduce the excretion of calcium in the urine.

IRISH ORTHOPAEDIC CLUB

A meeting of the Irish Orthopaedic Club was held at the Orthopaedic Hospital, Croom, County Limerick, on May 19, 1962.

McMurray and his osteotomy-Mr I. D. Kitchen, guest speaker from Lancaster, recalled some personal memories of Professor T. P. McMurray. He considered that despite the variety of operations now available the McMurray osteotomy was still the operation of choice for unilateral osteoarthritis of the hip, as well as being invaluable as a salvage procedure for ununited cervical fractures. Important points were: 1) that in the original technique using a plaster spica there should be wide abduction of the hip; 2) that when a Wainwright spline was used it should penetrate the upper cortex of the neck.

Choice of operation for osteoarthritis of the hip-Mr W. de Wytt (Navan) had studied a series of cases in which surgery had been followed by unsatisfactory results, in an endeavour to determine the

vol. 44 B, NO. 3, AUGUST 1962 
reasons for failure. He summarised his findings as follows. Arthrodesis was suitable only for cases in which the spine and opposite hip were mobile and likely to remain so. For V-arthrodesis the hip must be in good position: the best results were obtained with a short neck and stiff hip. Brittain's arthrodesis should be avoided when there was any tendency to osteoarthritis of the spine, because of the long period required in plaster. The Charnley arthrodesis required a long neck and shallow acetabulum: it was ideal for a mobile unstable hip. Arthroplasty had the drawback that a completely painless and stable hip was seldom obtained. The Fitzgerald replacement arthroplasty was suitable only when the expectation of life is not more than five years. The steel head arthroplasty required a deep acetabulum, solid pelvic bone and a cooperative patient. The Girdlestone arthroplasty was considered suitable for rheumatoid arthritis, in which there was always a tendency for the hip to dislocate, and also for cases of failed replacement arthroplasty. The Batchelor arthroplasty was suitable only for bilateral disease because of the shortening involved: the results were satisfactory, but four operations were required. Displacement osteotomy required for a favourable result a range of flexion of half the normal range, and an adducted or adductable hip. The muscle release operation was useful when the patient was unfit for more radical surgery.

Basic principles of muscle mechanics-Professor M. A. MacConaill (Cork), the second speaker, described modern methods of investigating the laws governing the actions of muscles, and the principles now known to underly their behaviour in varying circumstances. He described the work of Basmajian's school and of Bearn, which showed that in the shoulder the supraspinatus muscle, because of the direction of its pull, had to take by far the greatest loads with the hanging arm, stressing that its main attachment was to the joint capsule and only indirectly to the bone. These two facts, and the consequent strain thrown upon the upper part of the capsule of the joint, explained the frequency of fatigue and strain of the muscle.

The action of the sternomastoid and the treatment of congenital torticollis-Mr J. P. Kelly (Croom) showed, with the aid of a film, that in addition to flexing the head to the same side and turning it to the opposite side, the sternomastoid muscle, acting with its fellow, was a flexor of the neck, and not, as sometimes described, an extensor. He felt that in stretching a tight sternomastoid muscle lateral flexion was the most important action.

Club foot $-M r J . P$. Kelly recalled Robert Jones's teaching that early and full over-correction was the best safeguard against relapse in the treatment of club feet. He strapped the feet in the fully over-corrected position for at least three weeks in order to allow adaptive growth to take place.

\section{NEW ZEALAND}

\section{AUSTRALIAN AND NEW ZEALAND ORTHOPAEDIC ASSOCIATIONS}

The first combined meeting of the Australian and New Zealand Orthopaedic Associations was held at Wairakei in the heart of New Zealand's geothermal wonderland from February 5 to 8, 1962. The president of the New Zealand Orthopaedic Association, Mr J. Kennedy Elliott (Wellington), welcomed the president of the Australian Orthopaedic Association, Mr F. H. McC. Callow (Newtown, New South Wales), and fourteen other fellows of the Australian Association, many of whom were accompanied by their wives. Cablegrams wishing success to the meeting were received from $\mathrm{Mr} \mathrm{H}$. Jackson Burrows and Professor Bryan McFarland, both honorary fellows of the New Zealand Orthopaedic Association. The following papers were presented.

The calcaneum, keystone to the foot-Mr Rex Blunden (Christchurch) described the normal anatomy of the calcaneum and said that congenital anomalies such as calcaneo-navicular fusion profoundly affected the function of the foot. In talipes equino-varus the calcaneum was displaced medially on its long axis, and in flat foot the reverse obtained. The key to the successful correction of these deformities lay in the restoration of the calcaneum to its normal position relative to its long axis. He advocated wedge osteotomy on the lateral side of the calcaneum for relapsing club foot, and the Grice operation for flat foot. Mr C. M. Maxwell (Sydney) agreed with the Grice subtalar arthrodesis for flat feet. He did not like soft-tissue operations in club foot because in his hands 25 per cent of them came to triple arthrodesis. Congenital lesions such as calcaneo-navicular bars often caused no symptoms, and he believed that when symptoms occurred triple arthrodesis offered the best solution. Mr T. B. McMurray (Little Bay) said that in his experience 50 per cent of the grafts used in the Grice operation absorbed within five years.

Giant-cell tumour (osteoclastoma) of bone- $\mathrm{Mr} \mathrm{H}$. C. Barry (Sydney) had reviewed the treatment of primary bone tumours by himself and several colleagues in the teaching hospitals in Sydney. Giant-cell tumours of the skull and jaw and all tumours of multicentric origin were excluded. There were ninety-eight osteosarcomata, thirty chondrosarcomata and twenty-six osteoclastomata. Among 
patients with osteosarcoma there were only seven five-year survivors. The difficulties and confusion that still surrounded the classification and treatment of true giant-cell tumours were emphasised because it was essential to distinguish them from the many conditions in which giant cells might be found, such as bone cysts, osteitis fibrosa, aneurysmal bone cysts and non-osseous fibromas of bone. In diagnosis the age of the patient, the clinical and radiographic appearances and the pathological findings all had to agree. The disease was uncommon under the age of twenty and there was none over fifty. The common sites were well known; most cases described in the vertebrae were really aneurysmal bone cysts, and true giant-cell tumours of bone were rarer than was commonly thoughtone case per million population per year was a working guide. The twenty-six cases had been analysed but no firm conclusions could be drawn. It was necessary to modify the views on this tumour which existed until a decade ago. The ever present risk of malignant change put a great responsibility on the surgeon. Resection, if possible, was the best treatment, but for most tumours near the knee treatment should at first be conservative, either by local removal or by irradiation, but not both. When the function of the leg was impaired because of a large tumour, a pathological fracture or stiffness, amputation was advised. Once the tumour had recurred its benign nature could no longer be trusted and amputation was advisable. Mr P. C. Grayson (Palmerston North) did not think radiotherapy had much place in treatment, and $M r O$. R. Nicholson (Auckland) stressed the danger of giving a prognosis on the histological appearances.

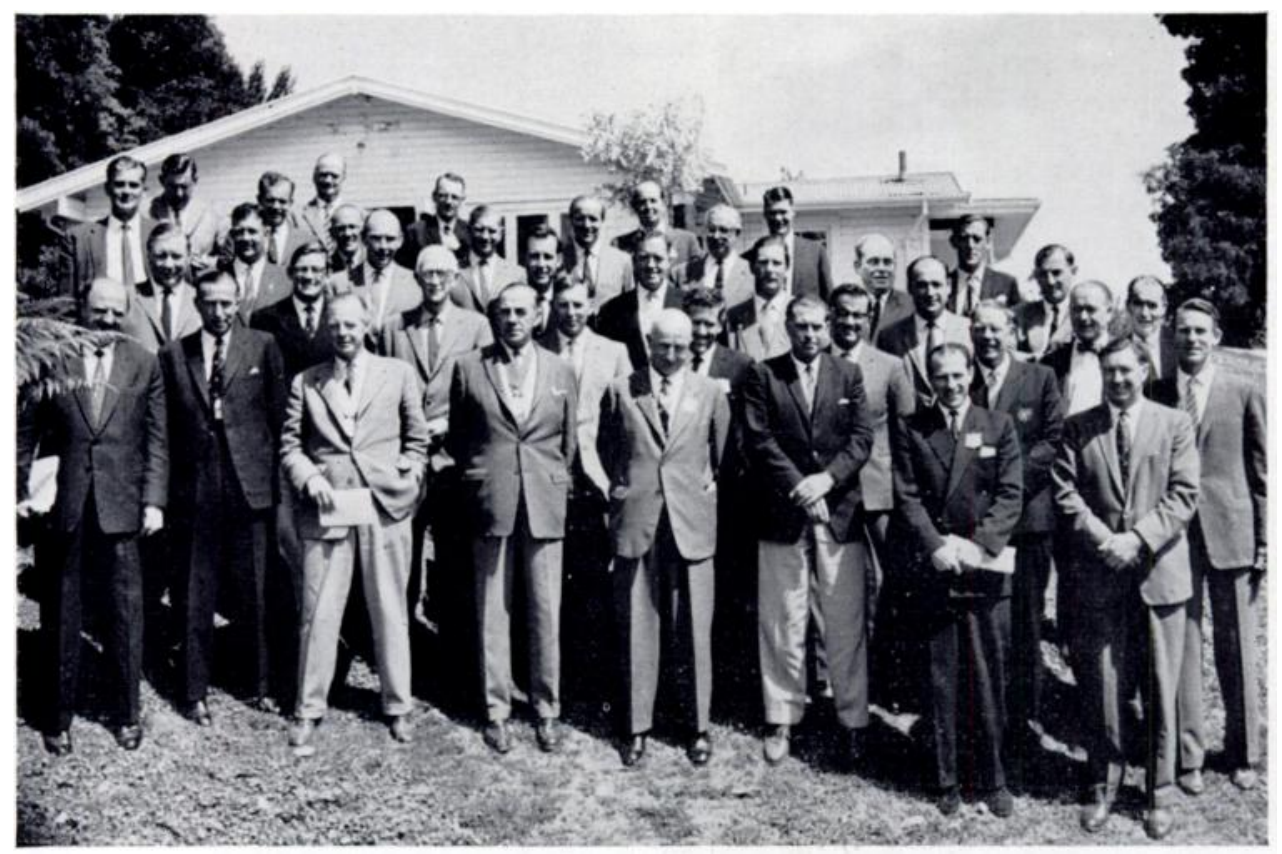

A group photographed during the combined meeting of the Australian and New Zealand Orthopaedic Associations.

Comminuted fractures of the femur-Mr P. M. Seglov (Sydney) recognised six main problems with this fracture when caused by high speed road accidents: 1 ) difficulty in reduction and in its maintenance: 2 ) another injury in the same leg; 3) associated vascular damage; 4) delayed union; 5) severe joint involvement with subsequent stiffness; and 6) associated injuries in other parts of the body. He described six such fractures which presented unusual difficulties. There seemed no easy solution to the problems, and each had to be dealt with on its merits. $M r W . A$.J. Pike (Auckland) believed that the more injuries a patient had the more advisable it was to use internal fixation. He had found a slotted plate and Phemister-type grafts useful. $M r O$. R. Nicholson (Auckland) stressed the need to use the Phemister type of graft as soon as union seemed delayed. $M r$ B. T. Keon-Cohen (Melbourne) said that it was easy to maintain position by skeletal traction, but traction should be maintained for a long time to avoid the concertina effect produced by collapse before consolidation.

Primary bone grafting of fractures of the forearm-Mr W.J. Betts (Adelaide) had found that conservative treatment of these fractures often resulted in slow union, with postero-medial bowing and non-union in 30 per cent. He had been impressed with the rate of union after onlay grafting. Conservative reduction and immobilisation in plaster were tried in all cases, but if the fracture was unstable open

VOL. 44 B, NO. 3, AUGUSt 1962 
reduction with tibial bone grafting was done, preferably ten to fourteen days after the injury. Thirty grafts had been done, with one failure from infection and loss of the graft. Complications were infection (two cases), tourniquet paralysis (one case), prominence of screws necessitating their removal (three cases), severe loss of rotation (two cases) and non-union (one case). The functional results were satisfactory in all but two patients. Mr J. R. Kirker (Auckland) disagreed with this method on two grounds. Firstly, he thought an onlay bone graft made an inefficient plate; and secondly, this was the least satisfactory site for grafting. He preferred slotted plates and cancellous onlay grafts from the ilium. $M r H$. C. Barry (Sydney) said that the radius should never be plated without adding iliac bone. $M r$ B. T. Keon-Cohen (Melbourne) said it was unwise to use tibial grafts when there had been any previous infection. $M r J$. Kennedy Elliott (Wellington) thought it reasonable to plate both bones initially and to deal with non-union by cancellous onlay grafting if it occurred.

Congenital pseudarthrosis of the clavicle-Mr A. J. Alldred (Dunedin) described this condition. The paper will be published in full in a subsequent number of the Journal.

Slipped upper femoral epiphysis-Mr R. H. Dawson (Palmerston North) reported the results of the treatment of this condition in thirty-nine hips since 1953. He had tried conservative treatment by traction. Operative treatment had been by cervical osteotomy for a severe slip and simple SmithPetersen nailing for a less severe slip. Conservative treatment gave poor results and cervical osteotomy was followed in 80 per cent of cases by avascular necrosis. Twenty hips treated by nailing were satisfactory, with no avascular necrosis. Mr J. M. J. Jens (Ballarat) believed in reducing the acute (traumatic) slips. The difficulty in driving the pin into the hard femoral head could be overcome by using a hollow drill over the guide wirc. $M r B$. T. Keon-Cohen (Melbourne) said that in his hands 50 per cent of cervical osteotomies gave perfect results.

Cervical spine syndromes-Mr J. M. J. Jens (Ballarat) had reviewed 120 patients with cervical spondylosis. He outlined the widespread and varied range of symptoms that this condition could produce, including local and peripheral pain, headache, visual and aural effects and vascular disturbances. One hundred and five patients had been satisfactorily treated conservatively using a modified Glisson's sling and spreader, followed by a moulded leather collar. In the remaining fifteen operation had been considered because of severe and intractable pain. Twelve patients underwent spinal fusion. Mr Jens thought that this problem needed much further study before the widespread nature of the symptoms could be properly understood. Mr G. J. Taine (Napier) agreed. He often employed manipulation (with or without anaesthesia) which had even relieved patients of migraine.

The changing phase of vertebral osteomyelitis-Mr W. Parke (Gisborne) said that pyogenic osteomyelitis of the vertebral column was not common but was said to occur more frequently in adults than in children. He recognised two forms: first, the acute fulminating type with a high fever, toxicity and acute back pain perhaps radiating to the arms, abdomen or lower limbs; this was a type formerly seen in children. Secondly, a low-grade type, with few, if any, general symptoms but with backache and limitation of spinal movement; this type occurred mainly in adults. The etiology was still obscure and it was possible that a streptococcus or a yeast infection was responsible. He thought that the disc was primarily affected, and he did not accept the Batson hypothesis of retrograde venous spread, but believed that arterial septicaemia was the likely cause. In the acute case treatment was by the administration of wide-spectrum antibiotics, splintage and early laminectomy if cord symptoms developed. For the low-grade type he advised antibiotics and an adequate period of rest. He described patients with both types of vertebral osteomyelitis. $M r W . J$. Betts (Adelaide) said that the disease might simulate tuberculosis, but was of shorter duration. He believed that the infection occurred in the vertebral body alongside the disc to cause softening of bone and prolapse of disc material into the vertebral body. $M r G$. M. Bedbrook (Perth) stressed the high incidence of tetraplegia complicating osteomyelitis of the cervico-thoracic spine.

Observations on the pathology and natural history of traumatic paraplegia-Mr G. M. Bedbrook (Perth) had studied twenty-four necropsy specimens from patients with fracture-dislocations of the thoracolumbar and cervico-thoracic columns obtained from one day to twenty years after the injury. The most important lesion, that in the neural tissue, was always over a length of the cord. Often there were cysts, and in certain injuries the cord was crushed. There might be varying types of root damage, when arachnoiditis and peridural scarring were seen; it had already been proved that this scarring was made worse by operations. Oedema could seldom be shown at necropsy, but he believed that it could account for transitory worsening of paralysis Thrombosis was one cause of destruction. In the cerebrospinal fluid the protein was sometimes raised because of the extent of the lesion and not because of block, which might be only temporary. In a study of forty-two fracture-dislocations of the thoracolumbar column $\mathrm{Mr}$ Bedbrook had found that nearly all the patients eventually had a moderate deformity even after postural reduction. He concluded that in very few patients was operative intervention 
justified, and then it was usually for bony reasons. $\mathrm{Mr} O \mathrm{O}$. R. Nicholson (Auckland) stressed the difficulty of obtaining suitable necropsy material. He agreed with conservative management for most patients. Mr T. B. McMurray (Little Bay) believed, from an experience of more than 100 patients in South Africa, that operation was contra-indicated. In fracture-dislocations of the cervical spine with tetraplegia the survival rate was two and a half times as great if no attempt had been made to treat the spine. He believed that operation often interfered with any surviving blood vessels to the cord and irretrievably worsened the prognosis.

\section{NEW ZEALAND ORTHOPAEDIC ASSOCIATION}

Induction of President-At the conclusion of the joint meeting of the Australian and New Zealand Orthopaedic Associations the incoming president of the New Zealand Orthopaedic Association, Mr Rex Blunden (Christchurch), was inducted by the outgoing president, $\mathrm{Mr}$ J. Kennedy Elliott. Good wishes were extended to Mr Blunden by the President of the Australian Orthopaedic Association, Mr F. H. McC. Callow.

\section{ANNOUNCEMENTS}

\section{BRITISH ORTHOPAEDIC ASSOCIATION}

\section{MEETINGS IN 1963}

Arrangements have been made to hold the following meetings during 1963: Sheffield, May 16 to 18 ; London, September 26 to 28 (provisional date). Those wishing to submit papers for presentation at the spring meeting should send five copies of a short abstract (about 400 words) to the Honorary Secretary not later than January 15, 1963.

\section{TRAVELLING SCHOLARSHIPS}

The British Orthopaedic Association has decided to offer two Travelling Scholarships to the value of $£ 100$ each in 1963 to be used for a tour of suitable orthopaedic centres in the United Kingdom. It is envisaged that these Scholarships will be suitable for men of senior registrar grade, but will not necessarily be so restricted. Applications (twenty copies) from Members or Associates practising in the United Kingdom, setting out the object of the proposed visit, proposed itinerary, and previous clinical experience and contributions to research, and giving the names of two referees, who must be Fellows of the Association, should be sent to the Honorary Secretary of the British Orthopaedic Association at the Royal College of Surgeons, Lincoln's Inn Fields, London, W.C.2, by November 30, 1962.

\section{SOUTH AFRICAN ORTHOPAEDIC ASSOCIATION}

The next meeting of the South African Orthopaedic Association will be held from October 17 to 20, 1962, in Pretoria, South Africa. The guest speaker will be Professor Roland Barnes from Glasgow. Anyone wishing to attend the Congress should contact the Honorary Secretary, Dr I. S. de Wet, South African Orthopaedic Association, 127 Van Riebeek Medical Buildings, Schoeman Street, Pretoria, South Africa.

\section{SPANISH SOCIETY OF ORTHOPAEDIC SURGERY}

The Spanish Society of Orthopaedic Surgery and Traumatology will hold its Annual Congress in Madrid from October 8 to 11, 1962, under the Presidency of Dr Sanchis Olmos. The general subjects to be discussed are: 1) the treatment of leg length discrepancy; and 2) the emergency treatment of road injuries. Miscellaneous papers and medical films will also be presented. Official invitation has been extended to the German, French, Italian and Portuguese Orthopaedic Societies. Colleagues from other countries will also take part. Arrangements for simulataneous translation from Spanish to French and German have been assured. The translation of other languages will depend on the number of visitors from other countries. Further information may be obtained from the Secretary of the Congress, Villanueva 11, Room 11, Madrid 1, Spain.

\section{SOCIÉTÉ INTERNATIONALE DE CHIRURGIE ORTHOPÉDIQUE ET DE TRAUMATOLOGIE}

The next meeting of the Société Internationale de Chirurgie Orthopédique et de Traumatologie (S.I.C.O.T.) will be held in Vienna from September 1 to 7, 1963. Inquiries should be addressed to the Secretary, M. Antoine Bailleux, 260 Avenue d’Auderghem, Bruxelles, Belgium.

VOL. 44 B, NO. 3, AUGUST 1962 